\title{
Cardiovascular Events in Cancer Patients Treated with Highly or Moderately Emetogenic Chemotherapy: Results from a Population-Based Study
}

\author{
Thao T. Vo and Jeanenne J. Nelson \\ Worldwide Epidemiology, GlaxoSmithKline, 5 Moore Drive, Mailstop 17.2124.2A, Research Triangle Park, Durham, \\ NC 27709-3398, USA \\ Correspondence should be addressed to Jeanenne J. Nelson, jeanenne.j.nelson@gsk.com
}

Received 4 November 2011; Accepted 27 January 2012

Academic Editor: Jon Fryzek

Copyright ( $\odot 2012$ T. T. Vo and J. J. Nelson. This is an open access article distributed under the Creative Commons Attribution License, which permits unrestricted use, distribution, and reproduction in any medium, provided the original work is properly cited.

Studies on cardiovascular safety in cancer patients treated with highly or moderately emetogenic chemotherapy (HEC or MEC), who may have taken the antiemetic, aprepitant, have been limited to clinical trials and postmarketing spontaneous reports. Our study explored background rates of cardiovascular disease (CVD) events among HEC- or MEC-treated cancer patients in a population-based setting to contextualize events seen in a new drug development program and to determine at a high level whether rates differed by aprepitant usage. Medical and pharmacy claims data from the 2005-2007 IMPACT National Benchmark Database were classified into emetogenic chemotherapy categories and CVD outcomes. Among 5827 HEC/MEC-treated patients, frequencies were highest for hypertension (16-21\%) and composites of venous (7-12\%) and arterial thromboembolic events (4$7 \%$ ). Aprepitant users generally did not experience higher frequencies of events compared to nonusers. Our study serves as a useful benchmark of background CVD event rates in a population-based setting of cancer patients.

\section{Background/Objective}

Chemotherapy-induced nausea and vomiting (CINV) negatively impacts the quality of life in cancer patients [1] and may lead to nonadherence to or dose reductions in chemotherapy [2]. Potential cardiac effects of antiemetics warrant special attention, given an estimated $13-60 \%$ burden of cardiovascular-related diseases that increases with age, among cancer patients [3-5]. Cardiovascular disease (CVD) can be preexisting, a result or natural progression of the malignancy or an adverse event resulting from chemotherapeutic treatment, such as anthracyclines and alkylating agents [6, 7]. For example, cyclophosphamide treatment has been associated with a 7-28\% incidence of heart failure, cisplatin has been associated with an $8.5 \%$ incidence of venous thromboembolism, including deep vein thrombosis and pulmonary embolism [8], and doxorubicin/daunorubicin has been associated with $0.5-3 \%$ incidence of arrhythmias [9].
Aprepitant is currently the only FDA-approved neurokinin (NK1) receptor antagonist (RA) that, when coadministered with other antiemetics, such as corticosteroids (dexamethasone) and serotonin $5-\mathrm{HT}_{3}$ receptor antagonists (e.g., dolasetron, granisetron, ondansetron, and palonosetron), augments the prevention of acute and, particularly, delayed CINV [10]. Although aprepitant has been shown to be generally well tolerated in clinical trials [11], isolated cases of serious adverse events, such as bradycardia [12] and hypertension [13], have been reported in two highly emetogenic chemotherapy (HEC) studies comparing aprepitant plus ondansetron and dexamethasone to the standard regimen of ondansetron and dexamethasone, alone $[14,15]$. Other cardiovascular events $(>0.5 \%$ and greater than standard therapy), regardless of causality, have also been reported in patients treated with the aprepitant regimen in either HEC or MEC studies, including myocardial infarction, tachycardia, 
TABLE 1: Characteristics of 5827 patients with select* cancers and $\leq 4$ cycles of HEC, MEC, or HEC/MEC combined, 2005-2007 IMPACT National Benchmark Database (OptumInsight, Eden Prairie, MN).

\begin{tabular}{|c|c|c|c|c|c|c|c|c|c|c|c|c|}
\hline \multirow[t]{2}{*}{ Characteristic } & \multicolumn{3}{|c|}{$\begin{array}{l}\text { HEC and/or MEC } \\
\qquad(N=5827)\end{array}$} & \multicolumn{3}{|c|}{$\begin{array}{l}\text { HEC only } \\
(N=330)\end{array}$} & \multicolumn{3}{|c|}{$\begin{array}{l}\text { MEC only } \\
(N=5269)\end{array}$} & \multicolumn{3}{|c|}{$\begin{array}{l}\text { HEC/MEC combined } \\
\qquad(N=228)\end{array}$} \\
\hline & Total & $\begin{array}{l}\text { No } \\
\text { Aprep }\end{array}$ & Aprep & Total & $\begin{array}{l}\text { No } \\
\text { Aprep }\end{array}$ & Aprep & Total & $\begin{array}{l}\text { No } \\
\text { Aprep }\end{array}$ & Aprep & Total & $\begin{array}{l}\text { No } \\
\text { Aprep }\end{array}$ & Aprep \\
\hline$\%$ Male & 21.90 & 27.56 & 11.14 & 45.45 & 52.73 & 38.18 & 19.57 & 25.59 & 7.52 & 41.67 & 47.48 & 32.58 \\
\hline$\%$ Female & 78.10 & 72.44 & 88.86 & 54.55 & 47.27 & 61.82 & 80.43 & 74.41 & 92.48 & 58.33 & 52.52 & 67.42 \\
\hline Mean age (yrs) & 54.7 & 56.3 & 51.7 & 54.8 & 55.8 & 53.8 & 54.6 & 56.2 & 51.4 & 56.2 & 57.1 & 54.8 \\
\hline$\%$ Age $\geq 60$ & 32.52 & 38.22 & 21.69 & 35.15 & 38.79 & 31.52 & 32.23 & 38.29 & 20.10 & 35.53 & 35.97 & 34.83 \\
\hline$\%$ Age $\geq 65$ & 14.35 & 18.31 & 6.82 & 14.85 & 16.97 & 12.73 & 14.22 & 18.33 & 5.98 & 16.67 & 19.42 & 12.36 \\
\hline$\%$ Breast cancer & 60.41 & 50.98 & 78.31 & 26.67 & 19.39 & 33.94 & 64.07 & 53.74 & 84.74 & 24.56 & 18.71 & 33.71 \\
\hline$\%$ Colorectal cancer & 7.00 & 9.30 & 2.64 & 6.97 & 6.67 & 7.27 & 6.95 & 9.45 & 1.94 & 8.33 & 8.63 & 7.87 \\
\hline $\begin{array}{l}\% \text { Head and neck } \\
\text { cancer }\end{array}$ & 5.85 & 5.74 & 6.07 & 26.97 & 26.67 & 27.27 & 3.93 & 4.18 & 3.42 & 19.74 & 20.14 & 19.10 \\
\hline$\%$ Lung cancer & 25.73 & 32.91 & 12.09 & 36.67 & 44.85 & 28.48 & 24.05 & 31.51 & 9.11 & 48.68 & 53.96 & 40.45 \\
\hline$\%$ Ovarian cancer & 5.59 & 6.47 & 3.93 & 6.67 & 7.27 & 6.06 & 5.60 & 6.55 & 3.70 & 3.95 & 3.60 & 4.49 \\
\hline $\begin{array}{l}\% \text { Prior history of } \\
\text { CVD }^{\ddagger}\end{array}$ & 50.76 & 55.28 & 42.19 & 61.52 & 64.85 & 58.18 & 49.86 & 54.68 & 40.21 & 56.14 & 58.99 & 51.69 \\
\hline
\end{tabular}

* Breast, colorectal, head and neck, lung, and ovarian cancers.

${ }^{\ddagger}$ Prior history of CVD is defined as a diagnosis of any of the following prior to the start of HEC and/or MEC: hypertension, diabetes, coronary artery disease, myocardial infarction, congestive heart failure, stroke, transient ischemic attack, deep vein thrombosis (DVT), and pulmonary embolism (PE).

Note: percentage by type of cancer may add to $>100 \%$ due to patients having multiple cancer types.

deep vein thrombosis, flushing, hypertension, and hypotension [12]. However, results from clinical trials may not reflect those observed in clinical practice, and population-based studies of the cardiovascular effects of aprepitant are lacking. We aimed to quantify background rates of several CVDrelated events among HEC and/or MEC-treated cancer patients for two purposes: to understand expected rates among cancer patients in order to contextualize events which may be seen in our clinical development program of a similar patient population with a similar drug and to further understand at a high level whether rates differed by the decision to treat with aprepitant, recognizing that users versus nonusers may differ with respect to disease severity, access to care, preexisting conditions, and other factors. Therefore, the objective of this study was to use a large, US healthcare claims database to assess the frequency of CVD-related events among HEC and/or MEC-treated cancer patients and to determine if the frequency was impacted by the decision to treat with aprepitant.

\section{Methods}

A retrospective cohort study of adult patients with select cancers, treated with HEC and/or MEC, was conducted using 2005-2007 data from the IMPACT National Benchmark Database (OptumInsight, Eden Prairie, MN), a comprehensive, deidentified healthcare claims database that is representative of the nonelderly, insurance-carrying population in the United States. At the time of our analysis, the database contained inpatient/outpatient and pharmacy claims, a subset of lab results and enrolment information on over 82 million members from 45 healthcare plans serving nine census regions from 1997 to 2007. The IMPACT database is HIPAA compliant and features encrypted member and provider IDs.

The study included several cancer types commonly treated with HEC or MEC, namely, breast, colorectal, head and neck, lung, and ovarian cancer patients (Table 4), in adults with $\leq 4$ cycles of HEC and/or MEC as documented in one or more claims in the year 2006. We choose $\leq 4$ cycles because two-thirds of all treated patients had up to and including 4 cycles. The study analysis period was defined as the first day of the first HEC and/or MEC cycle to 30 days past the first day of the last cycle. The start of a new cycle of chemotherapy was defined by a period of more than 7 days but less than 45 days between cycles. The start of treatment was the first HEC and/or MEC claim in 2006, with 3 months prior with no claim ("wash-in" period) to ensure that there was no CVD effect of HEC/MEC treatment in 2005 that was carried over into 2006. The end of treatment was reached after 45 days of no additional HEC and/or MEC claim following the last claim ("wash-out" period) to ensure that all CVD effects from HEC/MEC treatment in 2006 were captured. To illustrate, for patients whose first HEC or MEC claim was between January 1, 2006 and March 31, 2006, the enrolment criteria for inclusion in the study extended as far back as October 1, 2005. For patients whose last claim in 2006 was seen after December 1, 2006, enrolment into 2007 to look for further treatment and the 45 day "wash-out" period was required.

Data on aprepitant exposure and chemotherapy was obtained from the inpatient/outpatient and pharmacy claims. Chemotherapeutic agents were defined as HEC if they were associated with $>90 \%$ of treated patients having emesis, and 
TABLE 2: Cardiovascular-related events in 5827 patients with select* cancers and $\leq 4$ cycles of HEC, MEC, or HEC/MEC combined, 20052007 IMPACT National Benchmark Database (OptumInsight, Eden Prairie, MN).

\begin{tabular}{|c|c|c|c|c|c|c|c|c|}
\hline \multirow{2}{*}{$\begin{array}{l}\text { Cardiovascular and } \\
\text { thromboembolic events }\end{array}$} & \multicolumn{2}{|c|}{$\begin{array}{l}\text { HEC and/or MEC } \\
\qquad(N=5827)\end{array}$} & \multicolumn{2}{|c|}{$\begin{array}{l}\text { HEC only } \\
(N=330)\end{array}$} & \multicolumn{2}{|c|}{$\begin{array}{l}\text { MEC only } \\
(N=5269)\end{array}$} & \multicolumn{2}{|c|}{$\begin{array}{l}\text { HEC plus MEC } \\
\qquad(N=228)\end{array}$} \\
\hline & $n$ & $\%$ & $n$ & $\%$ & $n$ & $\%$ & $n$ & $\%$ \\
\hline Angina pectoris & 32 & 0.55 & 3 & 0.91 & 28 & 0.53 & 1 & 0.44 \\
\hline Arterial disorder & 9 & 0.15 & 2 & 0.61 & 7 & 0.13 & 0 & - \\
\hline Arterial occlusive disease & 2 & 0.03 & 0 & - & 2 & 0.04 & 0 & - \\
\hline $\begin{array}{l}\text { Arterial thromboembolic } \\
\text { (excluding chest pain/discomfort) }\end{array}$ & 254 & 4.36 & 23 & 6.97 & 220 & 4.18 & 11 & 4.82 \\
\hline $\begin{array}{l}\text { Arterial thromboembolic } \\
\text { (including chest pain/discomfort) }\end{array}$ & 881 & 15.12 & 72 & 21.82 & 754 & 14.31 & 55 & 24.12 \\
\hline Cardiac arrest & 25 & 0.43 & 4 & 1.21 & 19 & 0.36 & 2 & 0.88 \\
\hline Cardiac disorder & 3 & 0.05 & 0 & - & 3 & 0.06 & 0 & - \\
\hline Cardio-respiratory arrest & 27 & 0.46 & 4 & 1.21 & 21 & 0.40 & 2 & 0.88 \\
\hline Cardiogenic shock & 1 & 0.02 & 0 & - & 1 & 0.02 & 0 & - \\
\hline Cerebral ischemia & 62 & 1.06 & 8 & 2.42 & 53 & 1.01 & 1 & 0.44 \\
\hline Cerebrovascular accident & 52 & 0.89 & 3 & 0.91 & 49 & 0.93 & 0 & - \\
\hline Chest pain or discomfort & 719 & 12.34 & 62 & 18.79 & 610 & 11.58 & 47 & 20.61 \\
\hline Circulatory collapse & 14 & 0.24 & 1 & 0.30 & 13 & 0.25 & 0 & - \\
\hline Embolism & 97 & 1.66 & 8 & 2.42 & 83 & 1.58 & 6 & 2.63 \\
\hline Hypertension & 966 & 16.58 & 68 & 20.61 & 854 & 16.21 & 44 & 19.30 \\
\hline Hypotension & 149 & 2.56 & 11 & 3.33 & 126 & 2.39 & 12 & 5.26 \\
\hline Iliac artery embolism & 2 & 0.03 & 1 & 0.30 & 1 & 0.02 & 0 & - \\
\hline Increased platelets & 7 & 0.12 & 0 & - & 7 & 0.13 & 0 & - \\
\hline Intermittent claudication & 9 & 0.15 & 2 & 0.61 & 4 & 0.08 & 3 & 1.32 \\
\hline Myocardial infarction & 11 & 0.19 & 1 & 0.30 & 10 & 0.19 & 0 & - \\
\hline Myocardial ischemia & 11 & 0.19 & 0 & - & 11 & 0.21 & 0 & - \\
\hline Peripheral embolism & 38 & 0.65 & 4 & 1.21 & 30 & 0.57 & 4 & 1.75 \\
\hline Peripheral ischemia & - & - & 0 & - & 0 & - & 0 & - \\
\hline Sudden death & - & - & 0 & - & 0 & - & 0 & - \\
\hline Syncope & 140 & 2.40 & 12 & 3.64 & 117 & 2.22 & 11 & 4.82 \\
\hline Venous thromboembolic & 450 & 7.72 & 40 & 12.12 & 383 & 7.27 & 27 & 11.84 \\
\hline
\end{tabular}

* Breast, colorectal, head and neck, lung, and ovarian cancers.

MEC, if associated with 30-90\% of patients having emesis (Table 5). Chemotherapies were classified by a physician within our department using previously published criteria as guidance $[16,17]$. Cardiovascular outcomes of interest included arterial and venous thromboembolic events, individually as well as a composite event, as well as cardiac arrest, hypertension, hypotension, increased platelets, sudden death, and syncope (Table 4). Patient characteristics included gender, age, tumor type, and prior history of cardiovascular disease. Prior CVD was defined as the presence of a claim for hypertension, diabetes, coronary artery disease, myocardial infarction, congestive heart failure, ischemic stroke, transient ischemic attack, deep vein thrombosis, or pulmonary embolism anytime before HEC or MEC initiation.

Subjects who used either HEC or MEC were categorized into 3 emetogenic chemotherapy groups: HEC-only, MEConly, or HEC/MEC combined. All analyses, including the distribution (\% or mean) of patient characteristics and the frequency of CVD outcomes of interest, were tabulated overall and stratified by aprepitant usage and emetogenic category of chemotherapy. Analyses were not further stratified by number of chemotherapy cycles, however, due to insufficient sample size. This study was purely descriptive, and therefore, no formal statistical comparison was made between aprepitant users and nonusers. Rather, the data was visually inspected for noteworthy absolute differences of $\geq 5 \%$ or relative differences of $\geq 1.5$ times.

\section{Results}

The number of cancer patients with the cancer types of interest who had at least 3 months of continuous enrolment and pharmacy benefit, at least one HEC or MEC claim, and $\leq 4$ cycles of chemotherapy was 5827. Among these patients, the distribution of patients by cancer type was $60.4 \%$ with breast, $25.7 \%$ with lung, $7.0 \%$ with colorectal, 


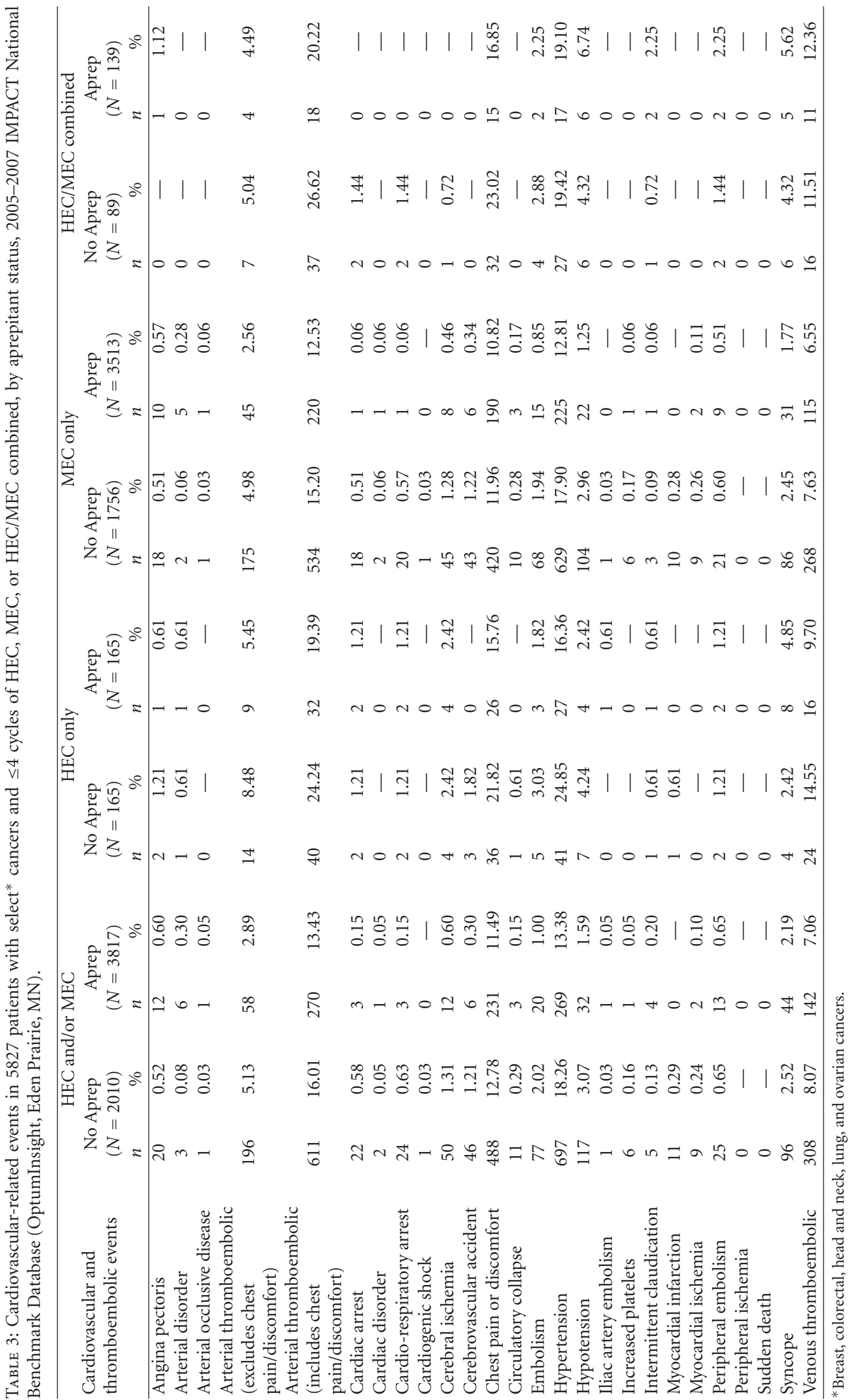


TABLE 4: ICD-9 codes for selected cancers and cardiovascular-related events.

\begin{tabular}{|c|c|}
\hline Cancer & ICD-9-CM code(s) \\
\hline Breast & $\begin{array}{l}174.0-174.6,174.8,174.9 \\
175,175.0,175.9\end{array}$ \\
\hline Colorectal & $\begin{array}{l}153,153.0-153.9,154 \\
154.0-154.3,154.8 \\
230.3-230.6\end{array}$ \\
\hline Head and neck & $\begin{array}{l}140.0-140.9,141.0-141.9 \\
142.0-142.9,143.0-143.9 \\
144.0-144.9,145.0-145.9 \\
146.0-146.9,147.0-147.9 \\
148.0-148.9,149.0-149.9 \\
161.0-161.9\end{array}$ \\
\hline Lung & $162.2-162.5,162.8,162.9$ \\
\hline Ovarian & 183.0 \\
\hline CVD-related events & ICD-9-CM code(s) \\
\hline \multicolumn{2}{|c|}{ Arterial Thromboembolic events } \\
\hline Angina pectoris & 413.x \\
\hline Arterial disorder & 459.9 \\
\hline Arterial occlusive disease & 362.34 \\
\hline Cardiac disorder & 997.1 \\
\hline Cardio-respiratory arrest & $427.5,799.1$ \\
\hline Cardiogenic shock & 785.51 \\
\hline Cerebral ischemia & $435,435.8,435.9,437.1$ \\
\hline Cerebrovascular accident & 436,437 \\
\hline Chest pain or discomfort & $586.5 x$ \\
\hline Circulatory collapse & $785.5,785.50$ \\
\hline Embolism & $\begin{array}{l}\text { 433, 434.x, 444.0-444.2, } \\
444.21,444.22,444.81 \\
444.89,444.9,445,445.01 \\
445.02,445.81,445.89\end{array}$ \\
\hline Iliac artery embolism & 444.81 \\
\hline Intermittent claudication & 440.21 \\
\hline Myocardial infarction & 410.x \\
\hline Myocardial ischemia & 414.8 \\
\hline Peripheral embolism & 444.x \\
\hline Peripheral ischemia & 414 \\
\hline Cardiac Arrest & 427.5 \\
\hline Hypertension & $\begin{array}{l}\text { 401.x, 405.x, 401.0, 401.1, } \\
\text { 401.9, 796.2 }\end{array}$ \\
\hline Hypotension & $458 . \mathrm{x}$ \\
\hline Increased platelets & $238.71,287.1$ \\
\hline Sudden death & $798,798.2$ \\
\hline Syncope & $780.0,780.2,780.9$ \\
\hline \multicolumn{2}{|l|}{ Venous thromboembolic events } \\
\hline Deep vein thrombosis & $\begin{array}{l}\text { 451.1, 451.11, 451.19, } \\
451.2,451.81,451.83, \\
451.84,453.1-453.4, \\
453.41,453.42,453.8,453.9\end{array}$ \\
\hline Phlebitis & $451 . x$ \\
\hline Phlebitis superficial & 451.1 \\
\hline
\end{tabular}

TABLE 4: Continued.

\begin{tabular}{ll}
\hline CVD-related events & ICD-9-CM code(s) \\
\hline Pulmonary embolism & $415.1,415.11,415.12$, \\
Superior vena cava occlusion & 415.19 \\
Thrombophlebitis & $459.2,901.2,38.8$ \\
Thrombophlebitis superficial & $451.0,451.82,671.2 \mathrm{x}$ \\
Varicophlebitis & $454.1,454.2,454.8$ \\
Vena cava thrombosis & 453.2 \\
Venous thrombosis & $453.0,453.4,453.9$ \\
\hline
\end{tabular}

$5.9 \%$ with head and neck, and 5.6\% with ovarian cancer (Table 1). Over $90 \%$ of patients had treatment by MEConly, followed by $5.7 \%$ with HEC-only and $3.9 \%$ with both HEC and MEC. Females comprised the majority across chemotherapy groups (55\% HEC-only; 80\% MEC-only; $58 \% \mathrm{HEC} / \mathrm{MEC}$ combination), and this gender difference was greater among those who took aprepitant compared to those who did not. The mean age ( $\sim 55$ years) was similar across the chemotherapy groups, as was the percentage aged 60 years or older. Those taking aprepitant, however, were 2 to 4.8 years younger, on average, and comprised fewer patients aged 60+ years compared to those who did not take aprepitant. In HEC-only patients, $32 \%$ of aprepitant users were $60+$ compared to $39 \%$ of nonusers; in MEC-only patients, the percentages were $20 \%$ versus $38 \%$, respectively; and in the HEC/MEC combination group, the percentages were $35 \%$ versus $36 \%$, respectively. Using a more traditional cutpoint of age 65+ years, similar results were found with aprepitant users having a smaller proportion of older patients than nonusers. Over half of patients had a history of CVD before their chemotherapy treatment, with the HEC-only group having a higher burden (62\%) compared to the MEConly group (50\%) and HEC/MEC combined group (56\%). The proportion with a prior history of CVD was lower in aprepitant users compared to nonusers.

Overall, the frequencies of cardiovascular and thromboembolic-related events following any HEC or MEC treatment were mostly driven by the MEC-only treatment group, comprising $90 \%$ of patients (Table 2). There were no sudden deaths. The frequencies of increased platelets, arterial disorder, arterial occlusive disease, cardiac disorder, cardiogenic shock, iliac artery embolism, intermittent claudication and peripheral ischemia were low $(n \leq 10)$ in this cohort.

Hypertension occurred in $16 \%$ of the MEC-only chemotherapy group and was slightly higher among the smaller HEC-only and HEC/MEC combination groups. Chest pain or discomfort occurred in $12 \%$ of the MEC-only patients, in $19 \%$ of HEC-only patients, and in $21 \%$ of combined HEC/MEC patients. All other single adverse CVD events occurred at a frequency less than 5\%, including MI and cerebrovascular accident, with the exception of hypotension, which occurred in $5.3 \%$ of those treated with HEC/MEC combined. The composite measure for arterial thromboembolic events, excluding chest pain and discomfort, ranged from $4 \%$ among the MEC-only group to $7 \%$ in the HEC-only 
group. The composite of venous thromboembolic events was $12 \%$ for the HEC-only and the HEC/MEC combined groups and $7 \%$ for the MEC-only group.

Stratified by the decision to include aprepitant in the antiemetic regimen (Table 3 ), the analysis demonstrated that in the MEC-only treated group, the composite of arterial thromboembolic events (without chest pain and discomfort), cardiac arrest, cardiorespsiratory arrest, cerebral ischemia, cerebrovascular accident, embolism, hypotension, and hypertension were more frequent $(\geq 1.5$ times or $\geq 5 \%$ absolute difference) among those who did not use aprepitant compared to those who did. Though based on small numbers $(n \leq 10)$, nonusers also had a higher rate of circulatory collapse (10 versus 3 ), increased platelet (6 versus 1 ), intermittent claudication (3 versus 1), and myocardial ischemia (9 versus 2). In all but two events (arterial disorder and arterial occlusive disorder) of the CVD-related categories among the MEC-only treated group, the frequency of CVD events was lower among aprepitant users versus nonusers.

For the HEC-only and the combined HEC/MEC chemotherapy groups, the numbers of individual cardiovascular-related events were generally too small $(n \leq 10)$ to make reliable comparisons across aprepitant status. However, where cells sizes were larger, HEC-only-treated patients who did not use aprepitant compared to users had a higher frequency of chest pain/discomfort as a diagnosis, a composite diagnosis of arterial thromboembolic events, excluding chest pain and discomfort, hypertension, and a composite measure of venous thromboembolic events. Though rare $(n \leq 10)$, additional events that were more frequent among nonusers compared to aprepitant users included angina pectoris (2 cases versus 1), embolism (5 versus 3 ), and hypotension (7 versus 4); in contrast, aprepitant users had a higher frequency of syncope ( 4 cases versus 8 ) than nonusers.

Among patients treated with both HEC and MEC, there was a higher frequency of chest pain and discomfort as a diagnosis and a composite diagnosis of arterial thromboembolic events, including chest pain, in nonusers of aprepitant compared to users. Users had a higher frequency of hypotension ( 6 cases versus 6 ), intermittent claudication ( 2 versus 1 ), and peripheral embolism (2 versus 2).

\section{Discussion}

The proportion of patients with CVD events was low $(\leq 5 \%)$ for many events across all chemotherapy groups, except for hypertension and the composite measures for arterial thromboembolic and venous thromboembolic events. This is in line with population-based data showing an annual incidence (per 1000 persons) of myocardial infarction of about 4 for men and 2 for women (Atherosclerosis Risk In Communities Surveillance data, 1987-2001), an annual incidence (per 1000 persons) of angina pectoris of 4 to over 8 among men ages $45-54$ and $65+$ years, respectively, and 0.9 to over 4 among women ages 45-54 and 65+ years, respectively (National Heart, Lung, and Blood Institute data, 2006), and a $33.6 \%$ prevalence of hypertension among US adults 20 years and older (National Health and Nutrition Examination Survey data, 2003-2006) [18].
CVD occurrences were slighter higher for those treated with HEC only or HEC/MEC combined than those treated with MEC-only. In addition, the HEC/MEC combined group experienced a slightly elevated frequency of hypotension compared to the HEC-only or MEC-only groups. It is noteworthy that sample sizes for the HEC-only and HEC/MEC combination groups are orders of magnitude smaller than the MEC-only group, and, thus, slightly higher percentages observed in these two groups may be due to sample variability.

Those who did not use aprepitant compared to those who did generally experienced higher frequencies of certain CVD-related events, namely, cardiac arrest, hypertension, hypotension, the composite of arterial thromboembolic events without chest pain/discomfort, and, in particular, cardio-respiratory arrest, cerebral ischemia, cerebrovascular accident, and embolism among the MEC-only treated group; arterial thromboembolic events with chest pain among the HEC/MEC combined chemotherapy groups; arterial thromboembolic events without chest pain, hypertension, and venous thromboembolic events in the HEC-only treated group. While there were some CVD-related events that occurred at a higher frequency among aprepitant users compared to nonusers, the absolute number of events was small, and most events were either similar across the two groups or higher in the nonaprepitant user group. In particular, in the MEC-only group, with its large numbers of users and nonusers, arterial disorder was higher among aprepitant users but the occurrence of all other events was either similar or lower among aprepitant users compared to nonusers. This may be explained by the fact that nonusers were more likely than users to be older and have a prior history of cardiovascular disease.

Aprepitant is a substrate and dose-dependent inhibitor and inducer of the cytochrome P4503A4 (CYP3A4) isoenzyme, and drugs metabolized by CYPA34 can have a potential drug interaction with aprepitant [19]. For example, cyclophosphamide is an anticancer agent that is metabolized to its active metabolites by CYPA34 [10] and is also associated with cardiac side effects such as acute heart failure, pericardial effusion, and arrhythmia [7]. Coadministration with aprepitant causes a decrease in plasma concentrations of the active metabolites of cyclophosphamide by $5 \%$ [20], a level which may not be clinically significant [10].

Some 5- $\mathrm{HT}_{3} \mathrm{RA}$ antiemetics (e.g., dolasetron, granisetron and ondansetron) have been associated with reversible, clinically insignificant changes to electrocardiographic (ECG) parameters (i.e., PR, QTS, QT, and JT intervals) [21], and their coadministration could have a diluting or enhancing effect on the occurrence of cardiovascular events.

As with all administrative databases, the claims data collected were not designed for research purposes, and, thus, are limited in scope and lack detailed clinical information available in medical records, such as ECG readings and lab data on MI-induced elevations of troponin, and so forth. A claim may represent a condition to be ruled out rather than diagnosis of the condition, itself. Discharge diagnosis for the identification of cardiovascular and thromboembolic events can have several sources of error, including variation 
TABLE 5: Chemotherapeutic agents according to HEC or MEC status.

\begin{tabular}{|c|c|c|c|}
\hline HEC or MEC & Chemotherapeutic agent & Strength & NDC or J-code \\
\hline \multicolumn{4}{|c|}{ Oral } \\
\hline MEC (low) & Arsenic & $10 \mathrm{MG} / 10 \mathrm{ML}$ & 60553011110 \\
\hline MEC (low) & Arsenic & $10 \mathrm{MG} / 10 \mathrm{ML}$ & 63459060010 \\
\hline MEC (low) & Carboplatin & $50 \mathrm{MG} / 0 \mathrm{ML}$ & 15321030 \\
\hline MEC (low) & Carboplatin & $150 \mathrm{MG} / 10 \mathrm{ML}$ & 15321130 \\
\hline MEC (low) & Carboplatin & $450 \mathrm{MG} / 40 \mathrm{ML}$ & 15321230 \\
\hline MEC (low) & Carboplatin & $50 \mathrm{MG}$ & 15321330 \\
\hline MEC (low) & Carboplatin & $150 \mathrm{MG}$ & 15321430 \\
\hline MEC (low) & Carboplatin & $450 \mathrm{MG}$ & 15321530 \\
\hline MEC (low) & Carboplatin & $10 \mathrm{MG} / \mathrm{ML}$ & 591333712 \\
\hline MEC (low) & Carboplatin & $10 \mathrm{MG} / \mathrm{ML}$ & 591333889 \\
\hline MEC (low) & Carboplatin & $10 \mathrm{MG} / \mathrm{ML}$ & 703324411 \\
\hline MEC (low) & Carboplatin & $10 \mathrm{MG} / \mathrm{ML}$ & 703324611 \\
\hline MEC (low) & Carboplatin & $10 \mathrm{MG} / \mathrm{ML}$ & 703324811 \\
\hline MEC (low) & Carboplatin & $10 \mathrm{MG} / \mathrm{ML}$ & 703324911 \\
\hline MEC (low) & Carboplatin & $50 \mathrm{MG}$ & 703326401 \\
\hline MEC (low) & Carboplatin & $150 \mathrm{MG}$ & 703326601 \\
\hline MEC (low) & Carboplatin & $450 \mathrm{MG}$ & 703326801 \\
\hline MEC (low) & Carboplatin & $10 \mathrm{MG} / \mathrm{ML}$ & 703424401 \\
\hline MEC (low) & Carboplatin & $10 \mathrm{MG} / \mathrm{ML}$ & 703424601 \\
\hline MEC (low) & Carboplatin & $10 \mathrm{MG} / \mathrm{ML}$ & 703424801 \\
\hline MEC (low) & Carboplatin & $10 \mathrm{MG} / \mathrm{ML}$ & 10019091202 \\
\hline MEC (low) & Carboplatin & $10 \mathrm{MG} / \mathrm{ML}$ & 10019091203 \\
\hline MEC (low) & Carboplatin & $50 \mathrm{MG}$ & 10019091501 \\
\hline MEC (low) & Carboplatin & $150 \mathrm{MG}$ & 10019091601 \\
\hline MEC (low) & Carboplatin & $450 \mathrm{MG}$ & 10019091701 \\
\hline MEC (low) & Carboplatin & $50 \mathrm{MG}$ & 50111096576 \\
\hline MEC (low) & Carboplatin & $150 \mathrm{MG}$ & 50111096676 \\
\hline MEC (low) & Carboplatin & $450 \mathrm{MG}$ & 50111096776 \\
\hline MEC (low) & Carboplatin & $50 \mathrm{MG}$ & 55390015001 \\
\hline MEC (low) & Carboplatin & $150 \mathrm{MG}$ & 55390015101 \\
\hline MEC (low) & Carboplatin & $450 \mathrm{MG}$ & 55390015201 \\
\hline MEC (low) & Carboplatin & $10 \mathrm{MG} / \mathrm{ML}$ & 55390015301 \\
\hline MEC (low) & Carboplatin & $10 \mathrm{MG} / \mathrm{ML}$ & 55390015401 \\
\hline MEC (low) & Carboplatin & $10 \mathrm{MG} / \mathrm{ML}$ & 55390015501 \\
\hline MEC (low) & Carboplatin & $10 \mathrm{MG} / \mathrm{ML}$ & 61703033918 \\
\hline MEC (low) & Carboplatin & $10 \mathrm{MG} / \mathrm{ML}$ & 61703033922 \\
\hline MEC (low) & Carboplatin & $10 \mathrm{MG} / \mathrm{ML}$ & 61703033950 \\
\hline MEC (low) & Carboplatin & $10 \mathrm{MG} / \mathrm{ML}$ & 61703033956 \\
\hline MEC (low) & Carboplatin & $150 \mathrm{MG}$ & 63323016721 \\
\hline MEC (low) & Carboplatin & $450 \mathrm{MG}$ & 63323016800 \\
\hline MEC (low) & Carboplatin & $10 \mathrm{MG} / \mathrm{ML}$ & 63323016905 \\
\hline MEC (low) & Carboplatin & $10 \mathrm{MG} / \mathrm{ML}$ & 63323016915 \\
\hline MEC (low) & Carboplatin & $10 \mathrm{MG} / \mathrm{ML}$ & 63323016945 \\
\hline MEC (low) & Carboplatin & $10 \mathrm{MG} / \mathrm{ML}$ & 63323017245 \\
\hline MEC (low) & Cyclophosphamide & $100 \mathrm{MG}$ & 13560693 \\
\hline MEC (low) & Cyclophosphamide & $200 \mathrm{MG}$ & 13561693 \\
\hline MEC (low) & Cyclophosphamide & $500 \mathrm{MG}$ & 13562693 \\
\hline MEC (low) & Cyclophosphamide & $500 \mathrm{MG}$ & 15050241 \\
\hline
\end{tabular}


Table 5: Continued.

\begin{tabular}{|c|c|c|c|}
\hline MEC (low) & Cyclophosphamide & $50 \mathrm{MG}$ & 15050301 \\
\hline HEC or MEC & Chemotherapeutic agent & Strength & NDC or J-code \\
\hline MEC (low) & Cyclophosphamide & $50 \mathrm{MG}$ & 15050302 \\
\hline MEC (low) & Cyclophosphamide & $25 \mathrm{MG}$ & 15050401 \\
\hline MEC (low) & Cyclophosphamide & $100 \mathrm{MG}$ & 15053941 \\
\hline MEC (low) & Cyclophosphamide & $200 \mathrm{MG}$ & 15054641 \\
\hline MEC (low) & Cyclophosphamide & $500 \mathrm{MG}$ & 15054741 \\
\hline MEC (low) & Cyclophosphamide & $25 \mathrm{MG}$ & 54412925 \\
\hline MEC (low) & Cyclophosphamide & $50 \mathrm{MG}$ & 54413025 \\
\hline MEC (low) & Cyclophosphamide & $25 \mathrm{MG}$ & 54808925 \\
\hline MEC (low) & Cyclophosphamide & $50 \mathrm{MG}$ & 54813025 \\
\hline MEC (low) & Cyclophosphamide & $500 \mathrm{MG}$ & 10019095501 \\
\hline MEC (low) & Cytarabine & $1 \mathrm{GM}$ & 9329501 \\
\hline MEC (low) & Cytarabine & $1 \mathrm{GM}$ & 703519401 \\
\hline MEC (low) & Cytarabine & $1 \mathrm{GM}$ & 55390013301 \\
\hline MEC (low) & Cytarabine & $1 \mathrm{GM}$ & 55390080801 \\
\hline MEC (low) & Daunorubicin & $20 \mathrm{MG}$ & 703503203 \\
\hline MEC (low) & Daunorubicin & $20 \mathrm{MG} / 4 \mathrm{ML}$ & 55390010810 \\
\hline MEC (low) & Daunorubicin & $20 \mathrm{MG}$ & 55390028110 \\
\hline MEC (low) & Daunorubicin & $2 \mathrm{MG} / \mathrm{ML}$ & 56146030101 \\
\hline MEC (low) & Daunorubicin & $2 \mathrm{MG} / \mathrm{ML}$ & 61958030101 \\
\hline MEC (low) & Doxorubicin & $20 \mathrm{MG}$ & 13109691 \\
\hline MEC (low) & Doxorubicin & $20 \mathrm{MG}$ & 13109694 \\
\hline MEC (low) & Doxorubicin & $20 \mathrm{MG} / 10 \mathrm{ML}$ & 13114691 \\
\hline MEC (low) & Doxorubicin & $20 \mathrm{MG} / 10 \mathrm{ML}$ & 13114694 \\
\hline MEC (low) & Doxorubicin & $20 \mathrm{MG} / 10 \mathrm{ML}$ & 13124691 \\
\hline MEC (low) & Doxorubicin & $50 \mathrm{MG} / 20 \mathrm{ML}$ & 13115679 \\
\hline MEC (low) & Doxorubicin & $50 \mathrm{MG} / 20 \mathrm{ML}$ & 13125679 \\
\hline MEC (low) & Doxorubicin & $50 \mathrm{MG}$ & 186153101 \\
\hline MEC (low) & Doxorubicin & $50 \mathrm{MG}$ & 10019092102 \\
\hline MEC (low) & Doxorubicin & $50 \mathrm{MG}$ & 55390023301 \\
\hline MEC (low) & Doxorubicin & $50 \mathrm{MG}$ & 55390024301 \\
\hline MEC (low) & Epirubicin & $2 \mathrm{MG} / \mathrm{ML}$ & 9509101 \\
\hline MEC (low) & Epirubicin & $2 \mathrm{MG} / \mathrm{ML}$ & 9509301 \\
\hline MEC (low) & Epirubicin & $50 \mathrm{MG}$ & 61703034735 \\
\hline MEC (low) & Idarubicin & $5 \mathrm{MG}$ & 13250694 \\
\hline MEC (low) & Idarubicin & $20 \mathrm{MG}$ & 13252686 \\
\hline MEC (low) & Idarubicin & $1 \mathrm{MG} / \mathrm{ML}$ & 13253678 \\
\hline MEC (low) & Idarubicin & $1 \mathrm{MG} / \mathrm{ML}$ & 13255667 \\
\hline MEC (low) & Idarubicin & $1 \mathrm{MG} / \mathrm{ML}$ & 13259691 \\
\hline MEC (low) & Ifosfamide & $1 \mathrm{GM}$ & 15055605 \\
\hline MEC (low) & Ifosfamide & $1 \mathrm{GM}$ & 15055611 \\
\hline MEC (low) & Ifosfamide & $1 \mathrm{GM}$ & 15055641 \\
\hline MEC (low) & Ifosfamide & $3 \mathrm{GM}$ & 15055741 \\
\hline MEC (low) & Ifosfamide & $5 \mathrm{GM} / 3 \mathrm{GM}$ & 703410048 \\
\hline MEC (low) & Ifosfamide & $1 \mathrm{GM}$ & 63323014210 \\
\hline MEC (low) & Irinotecan & $20 \mathrm{MG} / \mathrm{ML}$ & 9752901 \\
\hline MEC (low) & Irinotecan & $20 \mathrm{MG} / \mathrm{ML}$ & 9752902 \\
\hline MEC (low) & Pentostatin & $10 \mathrm{MG}$ & 62701080001 \\
\hline MEC (low) & Temozolomide & $5 \mathrm{MG}$ & 85124801 \\
\hline
\end{tabular}


Table 5: Continued.

\begin{tabular}{|c|c|c|c|}
\hline MEC (low) & Temozolomide & $5 \mathrm{MG}$ & 85124802 \\
\hline HEC or MEC & Chemotherapeutic agent & Strength & NDC or J-code \\
\hline MEC (low) & Temozolomide & $5 \mathrm{MG}$ & 85124803 \\
\hline MEC (low) & Temozolomide & $20 \mathrm{MG}$ & 85124401 \\
\hline MEC (low) & Temozolomide & $20 \mathrm{MG}$ & 85124402 \\
\hline MEC (low) & Temozolomide & $250 \mathrm{MG}$ & 85125201 \\
\hline MEC (low) & Temozolomide & $250 \mathrm{MG}$ & 85125202 \\
\hline MEC (low) & Temozolomide & $100 \mathrm{MG}$ & 85125901 \\
\hline MEC (low) & Temozolomide & $100 \mathrm{MG}$ & 85125902 \\
\hline MEC (low) & Temozolomide & $100 \mathrm{MG}$ & 85136601 \\
\hline MEC (low) & Temozolomide & $100 \mathrm{MG}$ & 85136602 \\
\hline MEC (low) & Temozolomide & $250 \mathrm{MG}$ & 85141701 \\
\hline MEC (low) & Temozolomide & $140 \mathrm{MG}$ & 85142501 \\
\hline MEC (low) & Temozolomide & $140 \mathrm{MG}$ & 85142502 \\
\hline MEC (low) & Temozolomide & $180 \mathrm{MG}$ & 85143001 \\
\hline MEC (low) & Temozolomide & $180 \mathrm{MG}$ & 85143002 \\
\hline MEC (low) & Temozolomide & $20 \mathrm{MG}$ & 85151901 \\
\hline MEC (low) & Temozolomide & $20 \mathrm{MG}$ & 85151902 \\
\hline MEC (low) & Temozolomide & $20 \mathrm{MG}$ & 54868414205 \\
\hline MEC (low) & Temozolomide & $20 \mathrm{MG}$ & 54868414206 \\
\hline MEC (low) & Temozolomide & $5 \mathrm{MG}$ & 54868534801 \\
\hline MEC (low) & Temozolomide & $100 \mathrm{MG}$ & 54868535002 \\
\hline MEC (low) & Temozolomide & $250 \mathrm{MG}$ & 54868535400 \\
\hline MEC (high) & Carmustine & $100 \mathrm{MG}$ & 15301238 \\
\hline MEC (high) & Carmustine & $100 \mathrm{MG}$ & 15301297 \\
\hline MEC (high) & Cisplatin & $50 \mathrm{MG} / 50 \mathrm{ML}$ & 15322022 \\
\hline MEC (high) & Cisplatin & $50 \mathrm{MG} / 50 \mathrm{ML}$ & 15322097 \\
\hline MEC (high) & Cisplatin & $1 \mathrm{MG} / \mathrm{ML}$ & 703574711 \\
\hline MEC (high) & Cisplatin & $1 \mathrm{MG} / \mathrm{ML}$ & 703574811 \\
\hline MEC (high) & Cisplatin & $1 \mathrm{MG} / \mathrm{ML}$ & 10019091001 \\
\hline MEC (high) & Cisplatin & $1 \mathrm{MG} / \mathrm{ML}$ & 10019091002 \\
\hline MEC (high) & Cisplatin & $50 \mathrm{MG} / 50 \mathrm{ML}$ & 55390011250 \\
\hline MEC (high) & Cisplatin & $50 \mathrm{MG} / 50 \mathrm{ML}$ & 55390041450 \\
\hline MEC (high) & Cisplatin & $1 \mathrm{MG} / \mathrm{ML}$ & 63323010351 \\
\hline MEC (high) & Cisplatin & $1 \mathrm{MG} / \mathrm{ML}$ & 63323010364 \\
\hline MEC (high) & Cisplatin & $1 \mathrm{MG} / \mathrm{ML}$ & 63323010365 \\
\hline MEC (high) & Cyclophosphamide & $1 \mathrm{GM}$ & 13563670 \\
\hline MEC (high) & Cyclophosphamide & $1 \mathrm{GM}$ & 15050541 \\
\hline MEC (high) & Cyclophosphamide & $1 \mathrm{GM}$ & 15054812 \\
\hline MEC (high) & Cyclophosphamide & $1 \mathrm{GM}$ & 15054841 \\
\hline MEC (high) & Cyclophosphamide & $1 \mathrm{GM}$ & 10019095601 \\
\hline MEC (high) & Cytarabine & $2 \mathrm{GM}$ & 55390013401 \\
\hline MEC (high) & Cytarabine & $2 \mathrm{GM}$ & 55390080901 \\
\hline MEC (high) & Cytarabine & $2000 \mathrm{MG} / 20 \mathrm{ML}$ & 61703031922 \\
\hline MEC (high) & Cytarabine & $2000 \mathrm{MG} / 20 \mathrm{ML}$ & 61703031922 \\
\hline MEC (high) & Dactinomycin & $0.5 \mathrm{MG}$ & 6329822 \\
\hline MEC (high) & Dactinomycin & $0.5 \mathrm{MG}$ & 67386081155 \\
\hline MEC (high) & Doxorubicin & $200 \mathrm{MG} / 100 \mathrm{ML}$ & 13116683 \\
\hline MEC (high) & Doxorubicin & $75 \mathrm{MG} / 37.0 \mathrm{ML}$ & 13117687 \\
\hline MEC (high) & Etoposide & $500 \mathrm{MG} / 20 \mathrm{ML}$ & 15306120 \\
\hline
\end{tabular}


Table 5: Continued.

\begin{tabular}{|c|c|c|c|}
\hline MEC (high) & Etoposide & $1 \mathrm{GM} / 50 \mathrm{ML}$ & 15306220 \\
\hline HEC or MEC & Chemotherapeutic agent & Strength & NDC or J-code \\
\hline MEC (high) & Etoposide & $500 \mathrm{MG} / 20 \mathrm{ML}$ & 55390029201 \\
\hline MEC (high) & Etoposide & $1000 \mathrm{MG} / 50 \mathrm{ML}$ & 55390029301 \\
\hline MEC (high) & Etoposide & $500 \mathrm{MG} / 20 \mathrm{ML}$ & 55390049201 \\
\hline MEC (high) & Etoposide & $1000 \mathrm{MG} / 50 \mathrm{ML}$ & 55390049301 \\
\hline MEC (high) & Melphalan & $2 \mathrm{MG}$ & 81004535 \\
\hline MEC (high) & Melphalan & $2 \mathrm{MG}$ & 173004535 \\
\hline MEC (high) & Melphalan & $50 \mathrm{MG}$ & 173013093 \\
\hline MEC (high) & Melphalan & $50 \mathrm{MG}$ & 173013093 \\
\hline MEC (high) & Melphalan & $2 \mathrm{MG}$ & 54868433901 \\
\hline MEC (high) & Melphalan & $2 \mathrm{MG}$ & 54868433902 \\
\hline MEC (high) & Melphalan & $2 \mathrm{MG}$ & 59572030250 \\
\hline MEC (high) & Methotrexate & $1 \mathrm{GM}$ & 55390014301 \\
\hline MEC (high) & Methotrexate & $1000 \mathrm{MG} / 40 \mathrm{ML}$ & 63323012140 \\
\hline MEC (high) & Methotrexate & $1 \mathrm{GM}$ & 63323012250 \\
\hline MEC (high) & Methotrexate & $1 \mathrm{GM}$ & 66479013929 \\
\hline MEC (high) & Procarbazine & $50 \mathrm{MG}$ & 4005301 \\
\hline MEC (high) & Procarbazine & $50 \mathrm{MG}$ & 54482005301 \\
\hline HEC & Cisplatin & $100 \mathrm{MG} / 100 \mathrm{ML}$ & 15322122 \\
\hline HEC & Cisplatin & $100 \mathrm{MG} / 100 \mathrm{ML}$ & 55390011299 \\
\hline HEC & Cyclophosphamide & $2 \mathrm{GM}$ & 13564670 \\
\hline HEC & Cyclophosphamide & $2 \mathrm{GM}$ & 15050641 \\
\hline HEC & Cyclophosphamide & 2GM & 15054941 \\
\hline HEC & Cyclophosphamide & 2GM & 10019095701 \\
\hline HEC & Dacarbazine & $200 \mathrm{MG}$ & 26815120 \\
\hline HEC & Dacarbazine & $200 \mathrm{MG}$ & 703507501 \\
\hline HEC & Dacarbazine & $200 \mathrm{MG}$ & 703507503 \\
\hline HEC & Dacarbazine & $200 \mathrm{MG}$ & 55390009010 \\
\hline HEC & Dacarbazine & $200 \mathrm{MG}$ & 61703032722 \\
\hline HEC & Dacarbazine & $100 \mathrm{MG}$ & 63323012710 \\
\hline HEC & Dacarbazine & $200 \mathrm{MG}$ & 63323012820 \\
\hline HEC & Mechlorethamine & $10 \mathrm{MG}$ & 6775331 \\
\hline HEC & Mechlorethamine & $10 \mathrm{MG}$ & 67386091151 \\
\hline HEC & Streptozocin & $1 \mathrm{GM}$ & 9084401 \\
\hline HEC & Streptozocin & $1 \mathrm{GM}$ & 703463601 \\
\hline \multicolumn{4}{|c|}{ Injectables } \\
\hline MEC (low) & Cyclophosphamide; oral & $25 \mathrm{MG}$ & $\mathrm{J} 8530$ \\
\hline MEC (low) & Injection, arsenic trioxide & $1 \mathrm{MG}$ & J9017 \\
\hline MEC (low) & Cyclophosphamide & $100 \mathrm{MG}$ & J9070 \\
\hline MEC (low) & Cyclophosphamide & $200 \mathrm{MG}$ & J9080 \\
\hline MEC (low) & Cyclophosphamide & $500 \mathrm{MG}$ & $\mathrm{J} 9090$ \\
\hline MEC (low) & Cyclophosphamide, lyopholized & $100 \mathrm{MG}$ & $\mathrm{J} 9093$ \\
\hline MEC (low) & Cyclophosphamide, lyopholized & $200 \mathrm{MG}$ & J9094 \\
\hline MEC (low) & Cyclophosphamide, lyopholized & $500 \mathrm{MG}$ & J9095 \\
\hline MEC (low) & Injection, epirubicin HCL & $2 \mathrm{MG}$ & $\mathrm{J} 9178$ \\
\hline MEC (low) & Injection, irinotecan & $20 \mathrm{MG}$ & J9206 \\
\hline MEC (low) & Injection, ifosfamide & $1 \mathrm{GM}$ & J9208 \\
\hline
\end{tabular}


TABle 5: Continued.

\begin{tabular}{|c|c|c|c|}
\hline HEC or MEC & Chemotherapeutic agent & Strength & NDC or J-code \\
\hline MEC (low) & Injection, idarubicin hydrochloride & $5 \mathrm{MG}$ & J9211 \\
\hline MEC (low) & Injection, mitoxantrone hydrochloride & Per $5 \mathrm{MG}$ & J9293 \\
\hline MEC (low) & Lomustine, oral & $10 \mathrm{MG}$ & S0178 \\
\hline MEC (high) & Injection, carboplatin & $50 \mathrm{MG}$ & $\mathrm{J} 9045$ \\
\hline MEC (high) & Injection, carmustine & $100 \mathrm{MG}$ & $\mathrm{J} 9050$ \\
\hline MEC (high) & Cisplatin, powder or solution & PER $10 \mathrm{MG}$ & J9060 \\
\hline MEC (high) & Cyclophosphamide & $1.0 \mathrm{GM}$ & J9091 \\
\hline MEC (high) & Cyclophosphamide, lyophilized & $1.0 \mathrm{GM}$ & J9096 \\
\hline MEC (high) & Injection, dactinomycin & $0.5 \mathrm{MG}$ & J9120 \\
\hline MEC (high) & Injection, melphalan hydrochloride & $50 \mathrm{MG}$ & J9245 \\
\hline MEC (high) & Pracarbazine hydrochloride, oral & $50 \mathrm{MG}$ & S0182 \\
\hline HEC & Cisplatin & $50 \mathrm{MG}$ & J9062 \\
\hline HEC & Cyclophosphamide & $2.0 \mathrm{GM}$ & J9092 \\
\hline HEC & Cyclophosphamide, lyophilized & $2.0 \mathrm{GM}$ & J9097 \\
\hline HEC & Dacarbazine & $100 \mathrm{MG}$ & J9130 \\
\hline HEC & Dacarbazine & $200 \mathrm{MG}$ & J9140 \\
\hline HEC & $\begin{array}{l}\text { Injection, mechlorethamine hydrochloride } \\
\text { (nitrogen mustard) }\end{array}$ & $10 \mathrm{MG}$ & J9230 \\
\hline HEC & Injection, streptozocin & $1 \mathrm{GM}$ & J9320 \\
\hline
\end{tabular}

MEC (low): moderately emetogenic chemotherapy associated with 30-60\% of patients having emesis, MEC (high): moderately emetogenic chemotherapy associated with $60-90 \%$ of patients having emesis, HEC: highly emetogenic chemotherapy associated with $>90 \%$ of patients having emesis.

in coding procedures, coding errors, incomplete coding, lack of specificity in available codes, and error in clinical diagnosis [22]. Misclassification of outcomes could lead to biased results. Nevertheless, the usefulness of claims data for certain CVD events has been assessed by other investigators. For example, a validation study of claim codes from a commercial insurance claims database, similar to IMPACT, against the gold standard medical records, showed a positive predictive value of $88 \%$ for both myocardial infarction and ischemic stroke [23].

This was a high-level analysis performed to provide overall background rates in a population of cancer patients similar to those under study in our clinical development program. It was not designed to draw causal inferences in differences between users of aprepitant and nonusers. The decision whether to treat with aprepitant most likely depends on many factors, such as the ability to pay for medications, physician experience, emetogenic potential of the chemotherapeutic agent, drug-drug interactions, and whether treatment is for acute or delayed CINV $[24,25]$. We did not attempt to unmask or correct for potential channeling bias, nor did we consider other possible confounding factors between the aprepitant user and nonuser groups, including drug severity and comorbidity. Our comparisons did not take into account possible confounding due to drugdrug interactions with specific cardiotoxic chemotherapeutic agents or other coadministered antiemetics. We did not account for chemotherapeutic drug dosages and did not have adequate sample size for assessing effects among individual cycles of chemotherapy. As a next step, we would have corrected for as many of these shortcomings as possible in a subsequent, more rigorous pharmacoepidemiology study had our clinical development program advanced.

Despite these limitations, this analysis provided a "real world" clinical practice baseline picture of the frequency of CVD-related events that occur during use of highly or moderately emetogenic chemotherapy, serving as a useful benchmark for safety signals identified during one of our clinical trial programs. Results should also serve for future supportive care studies. The preliminary information on experiences of the aprepitant antiemetic group compared to nonusers was helpful but should be interpreted cautiously.

\section{Conflict of Interests}

Both coauthors and all individuals named in the acknowledgments were employed by GlaxoSmithKline, Inc. throughout the conduct of the study.

\section{Acknowledgments}

The authors gratefully appreciate the contributions from the following individuals: Anne B. Dilley (project management and epidemiology), Douglas W. Clark, Monica G. Kobayashi and Bruce W. Althoff (database analytics), and Kathleen J. Beach (clinical consultation).

\section{References}

[1] E. Ballatori, F. Roila, B. Ruggeri et al., "The impact of chemotherapy-induced nausea and vomiting on health-related 
quality of life," Supportive Care in Cancer, vol. 15, no. 2, pp. 179-185, 2007.

[2] R. M. Navari, "Antiemetic control: toward a new standard of care for emetogenic chemotherapy," Expert Opinion on Pharmacotherapy, vol. 10, no. 4, pp. 629-644, 2009.

[3] M. F. de Marco, M. L. G. Janssen-Heijnen, L. H. van der Heijden, and J. W. W. Coebergh, "Comorbidity and colorectal cancer according to subsite and stage; a population-based study," European Journal of Cancer, vol. 36, no. 1, pp. 95-99, 2000.

[4] R. Yancik, "Cancer burden in the aged: an epidemiologic and demographic overview," Cancer, vol. 80, no. 7, pp. 1273-1283, 1997.

[5] C. Gridelli, F. Perrone, C. Gallo et al., "Chemotherapy for elderly patients with advanced non-small-cell lung cancer: the multicenter Italian lung cancer in the elderly study (MILES) phase III randomized trial," Journal of the National Cancer Institute, vol. 95, no. 5, pp. 362-372, 2003.

[6] D. L. Keefe, "The cardiotoxic potential of the $5-\mathrm{HT}_{3}$ receptor antagonist antiemetics: is there cause for concern?" Oncologist, vol. 7, no. 1, pp. 65-72, 2002.

[7] J. J. Monsuez, J. C. Charniot, N. Vignat, and J. Y. Artigou, "Cardiac side-effects of cancer chemotherapy," International Journal of Cardiology, vol. 144, no. 1, pp. 3-15, 2010.

[8] E. T. Yeh and C. L. Bickford, "Cardiovascular complications of cancer therapy: incidence, pathogenesis, diagnosis, and management," Journal of the American College of Cardiology, vol. 53, no. 24, pp. 2231-2247, 2009.

[9] V. B. Pai and M. C. Nahata, "Cardiotoxicity of chemotherapeutic agents. Incidence, treatment and prevention," Drug Safety, vol. 22, no. 4, pp. 263-302, 2000.

[10] K. K. Sankhala, D. M. Pandya, J. Sarantopoulos, S. A. Soefje, F. J. Giles, and S. P. Chawla, "Prevention of chemotherapy induced nausea and vomiting: a focus on aprepitant," Expert Opinion on Drug Metabolism and Toxicology, vol. 5, no. 12, pp. 1607-1614, 2009.

[11] C. H. Ruhlmann and J. Herrstedt, "Safety evaluation of aprepitant for the prevention of chemotherapy-induced nausea and vomiting," Expert Opinion on Drug Safety, vol. 10, no. 3, pp. 449-462, 2011.

[12] Merck \& Co. EMEND (aprepitant) capsules, prescribing information, (GENERIC). Ref Type: Electronic Citation, 2011, http://www.merck.com/index.html.

[13] D. G. Warr, S. M. Grunberg, R. J. Gralla et al., "The oral $\mathrm{NK}_{1}$ antagonist aprepitant for the prevention of acute and delayed chemotherapy-induced nausea and vomiting: pooled data from 2 randomised, double-blind, placebo controlled trials," European Journal of Cancer, vol. 41, no. 9, pp. 12781285, 2005.

[14] P. J. Hesketh, S. M. Grunberg, R. J. Gralla et al., "The oral neurokinin-1 antagonist aprepitant for the prevention of chemotherapy-induced nausea and vomiting: a multinational, randomized, double-blind, placebo-controlled trial in patients receiving high-dose cisplatin-the Aprepitant Protocol 052 Study Group," Journal of Clinical Oncology, vol. 21, no. 22, pp. 4112-4119, 2003.

[15] S. Poli-Bigelli, J. Rodrigues-Pereira, A. D. Carides et al., "Addition of the neurokinin 1 receptor antagonist aprepitant to standard antiemetic therapy improves control of chemotherapy-induced nausea and vomiting: results from a randomized, double-blind, placebo-controlled trial in Latin America," Cancer, vol. 97, no. 12, pp. 3090-3098, 2003.
[16] P. J. Hesketh, "Defining the emetogenicity of cancer chemotherapy regimens: relevance to clinical practice," Oncologist, vol. 4, no. 3, pp. 191-196, 1999.

[17] S. M. Grunberg, D. Osoba, P. J. Hesketh et al., "Evaluation of new antiemetic agents and definition of antineoplastic agent emetogenicity-an update," Supportive Care in Cancer, vol. 13, no. 2, pp. 80-84, 2005.

[18] D. Lloyd-Jones, R. J. Adams, T. M. Brown et al., "Executive summary: heart disease and stroke statistics - 2010 update: a report from the american heart association," Circulation, vol. 121, no. 7, pp. e46-e215, 2010.

[19] M. P. Curran and D. M. Robinson, "Aprepitant: a review of its use in the prevention of nausea and vomiting," Drugs, vol. 69, no. 13, pp. 1853-1878, 2009.

[20] M. E. de Jonge, A. D. R. Huitema, M. J. Holtkamp, S. M. van Dam, J. H. Beijnen, and S. Rodenhuis, "Aprepitant inhibits cyclophosphamide bioactivation and thiotepa metabolism," Cancer Chemotherapy and Pharmacology, vol. 56, no. 4, pp. 370-378, 2005.

[21] R. M. Navari and J. M. Koeller, "Electrocardiographic and cardiovascular effects of the 5-hydroxytryptamine 3 receptor antagonists," Annals of Pharmacotherapy, vol. 37, no. 9, pp. 1276-1286, 2003.

[22] H. T. Sorensen, Johnsen S. P., and B. Norgard, "Methodological issues in using prescription and other databases in pharmacoepidemiology," Norwegian Journal of Epidemiology, vol. 11, no. 1, pp. 13-18, 2001.

[23] P. M. Wahl, K. Rodgers, S. Schneeweiss et al., "Validation of claims-based diagnostic and procedure codes for cardiovascular and gastrointestinal serious adverse events in a commercially-insured population," Pharmacoepidemiology and Drug Safety, vol. 19, no. 6, pp. 596-603, 2010.

[24] M. S. Aapro, "Optimising antiemetic therapy: what are the problems and how can they be overcome?" Current Medical Research and Opinion, vol. 21, no. 6, pp. 885-897, 2005.

[25] L. S. Schwartzberg, "Chemotherapy-induced nausea and vomiting: which antiemetic for which therapy?” Oncology, vol. 21, no. 8, pp. 946-953, 2007. 


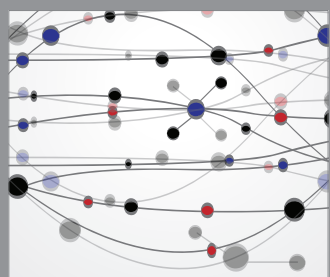

The Scientific World Journal
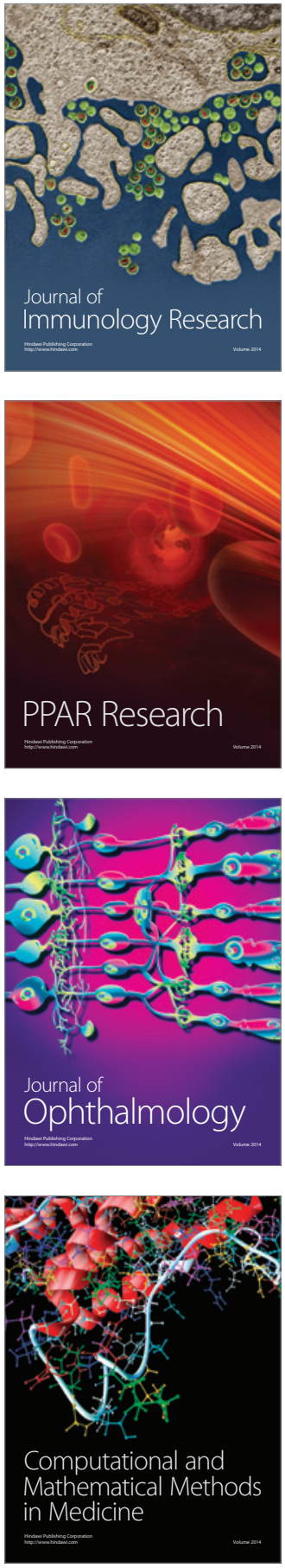

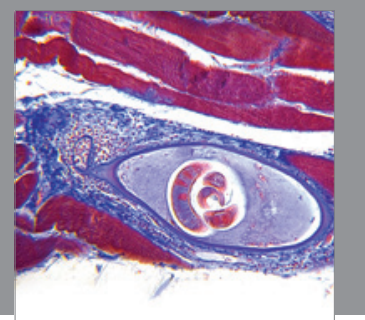

Gastroenterology

Research and Practice
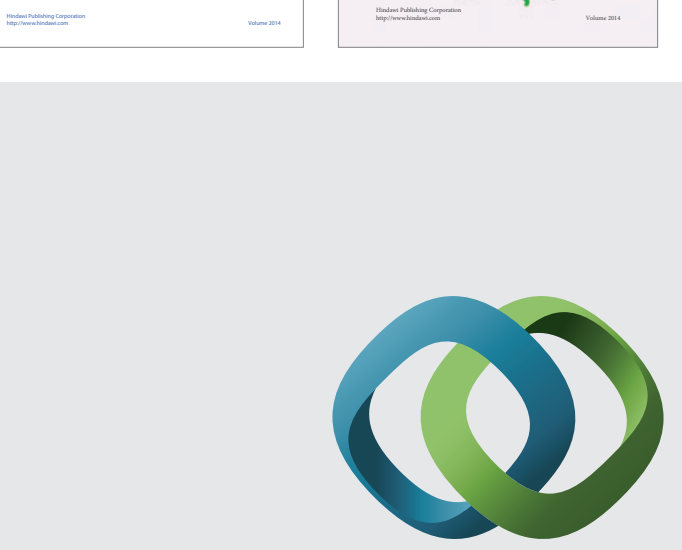

\section{Hindawi}

Submit your manuscripts at

http://www.hindawi.com
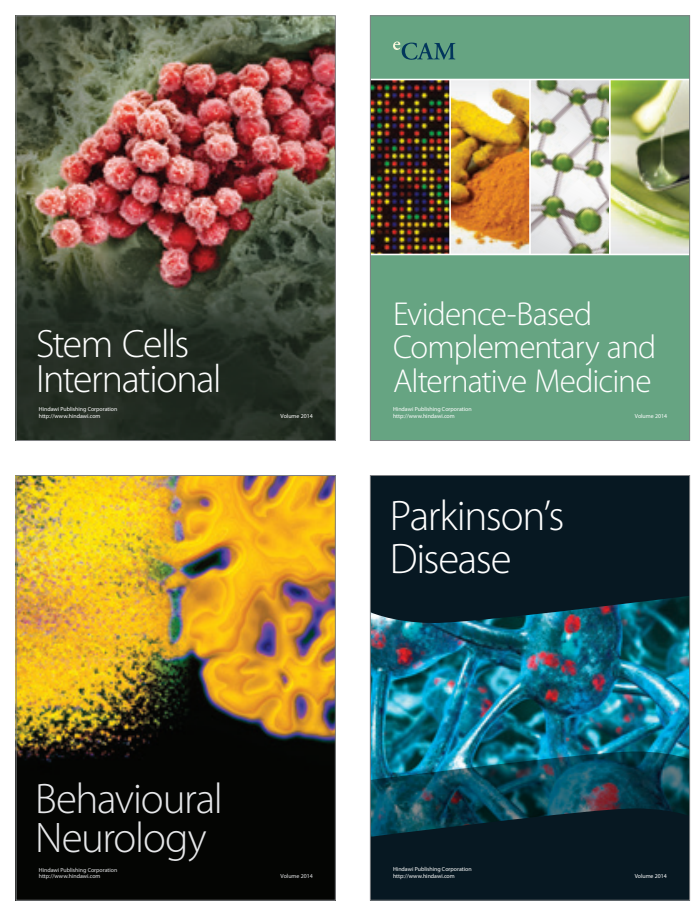

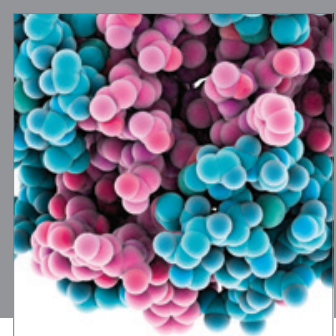

Journal of
Diabetes Research

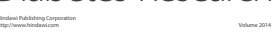

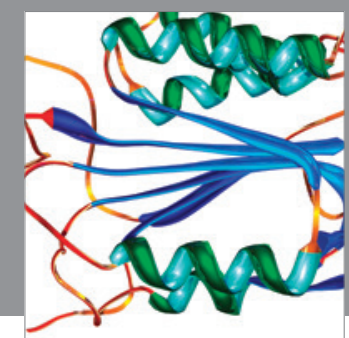

Disease Markers
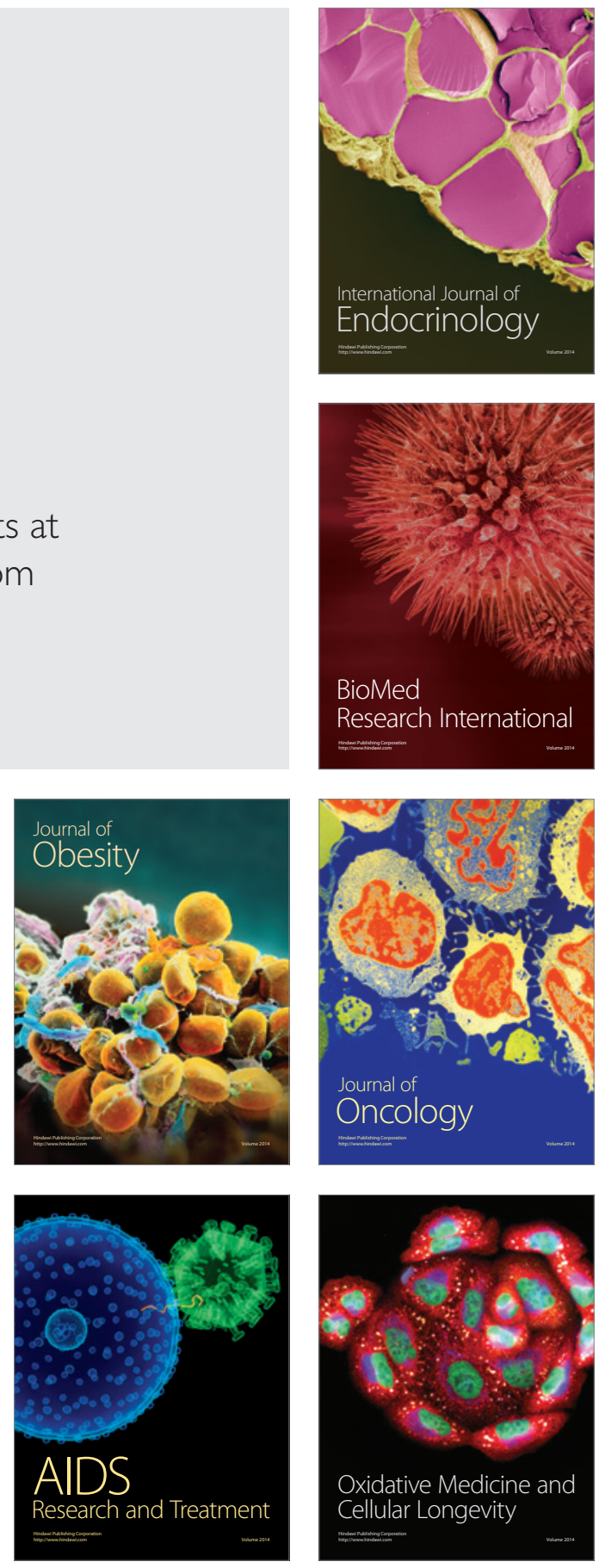